\title{
Creative Characteristics and Its Relation to Achievement and School Type among Jordanian Students
}

\author{
Alia Al-Oweidi \\ The World Islamic Sciences and Education University, Amman, Jordan \\ Email: aliaart2001@yahoo.com
}

Received August $5^{\text {th }}, 2012$; revised September $10^{\text {th }}, 2012$; accepted October $5^{\text {th }}, 2012$

\begin{abstract}
The purpose of this study is to investigate the creative characteristics among creative students in regular schools and its relation to achievement and school type variables as perceived by teachers. The sample of the study consisted of (176) male and female students with an age range ( 9 - 17 years), (127) of them are high achievers and (49) average achievers chosen purposefully from (11) schools, (7) private schools and (4) public schools. (67) teachers participated in evaluating the creative characteristics in students regardless of the academic achievement of students. The creative characteristics inventory is used to identify the creative characteristic in students. The findings of the study showed that there are apparent differences in the means between high achievers and average achievers on all creative characteristics. By using $(\mathrm{T})$ test to examine the differences between means, the findings showed that the differences were between high achievers and average achievers on the achievement variable within five domains: fluency, fantasy, problem sensitivity, originality and intuition for the favor of high achievers. Meanwhile, there were no significant statistical differences on the domains and other creative characteristics. With regard to school type, the findings showed significant differences on the means of the ambiguity, fantasy, curiosity, adventure and sense of humor for the favor of private schools. Moreover, there were significant differences in the mean of fluency, problem sensitivity, and independency for the favor of public schools.
\end{abstract}

Keywords: Creative Characteristics; High Achievers; Average Achievers; Public School; Private School

\section{Introduction}

Creativity can be defined as a series of mental abilities, it is a compound purposeful mental activity directed by the strong desire to generate or recognize ideas, alternatives, or possibilities that may be useful in solving problems, communicating with others, and entertaining ourselves and others. Gilford tried to describe creativity in a simple way by saying "Creativity in its narrowest meaning refers to the abilities of creative people". Guilford listed several assumptions related to the abilities which form creativity; he sees the creativity whatever its field is not the sole factor but it is a series of abilities which he mentioned as: fluency, flexibility, originality, and problem sensitivity, elaboration, evaluation, reorganizing and synthesis. It is worth to mention that creative children are those who display the following creative skills: 1) Fluency: which is an ability to produce a huge amount of idea, as this ability increases creativity; 2) Flexibility: is an adaptability to change instructions, freedom from inertia of thought and spontaneous shift of set; 3) Originality: it is the most advanced characteristic of creativity as it means novelty and uniqueness in providing the innovative product that fits the purpose or function it stands for; 4) Problem Sensitivity: is an ability to find problems and to aware needs for change or for new devices or methods; 5) Elaboration: is the realization or transformation of an idea, which may become very general or simple or in contrary very fantastic or enriched into details. Mostly, creative people display traits and characteristics that distinguish them from regular people. Those traits include: persistence, tendency for research and investigation, self-confidence, curiosity, openness on new experiences, managing mystery and complication, diversity of interests, lack of sophistication, achievement motivation, the need for support, praise and care, independency, humor, fantasy and ability to literature appreciation (Myers \& Torrance, 2003).

In this context Johnson (2004) mentioned some creative characteristics may be displayed by creative people. Those people may acquire deep and basic knowledge, prefer complication. Have the ability to form concepts and methods in a new way, have fluency in thinking, taking care of details, using unique solutions for problems, asking frequent questions, display the ability for constructive criticism like risks, prefer reading mystery novels, have a sense of humor and joke and enjoy their time when they are alone.

\section{Creativity and Academic Achievement}

Sometimes there is a weak relation between creativity and academic achievement; even this relation may be negative in some cases. This means that high competency in achievement is not a fundamental condition to accomplish creativity. This confirmed Torrance's argument that learning information and retrieving it is not a sufficient indicator for creativity.

In this concern, Einstein was quoted as saying: "I do not accumulate my memory of the facts that I can find it easily in one of the encyclopedias". Therefore, the schools (and teachers) do not reward creative students (Al-Srour, 2005).

The results of studies indicated that the most creative students have obtained medium or low averages in academic achievement, this is given to one of two reasons: either the school stages of education could not distinguish the various creative abilities! Or can not reward those students and satisfy their needs and their creative thinking. 
In Jordan, the educational services had developed rapidly as those services are not provided by the state only due to the emergence of the private sector as a strong competitor in this field.

And since there is an interest from parents to their children, in order to sharpen their personality in the academic, personal and creative aspects, many students had enrolled in private schools in Jordan under the assumptions that private schools provide services and activities better than public schools (Al-Srour, 2005).

Thus, the current study seeks to investigate the creative characteristics among creative students according to the type of school (private, public).

Hoi Man Ip, Chi Hang $\mathrm{Wu}$, Yim Cheng and Catherine McBride-Chang (2005) conducted a study in China to explore performances on three types of creativity tasks (real-world problem, figural, and verbal; in 22 6th-grade students and 22 university students from Hong Kong. As compared to 6th-grade students' scores, university students' scores (both quality and quantity) were significantly higher on the real-world problem and significantly lower on the figural task. On the verbal task, the groups did not differ. Results are interpreted in terms of an interaction between task structures and students' knowledge bases. Knowledge enhances one's performance in knowledgerich creativity tasks, whereas functional fixedness may occur in knowledge-lean tasks.

Lee \& Seo (2006) conducted a study to examine elementary teachers' understanding of creativity, in particular those who teach the gifted students. Forty-two elementary teachers were surveyed with an open-ended questionnaire to identify their understanding of creativity. Their answers were analyzed based on cognitive, personal, and environmental components of creativity. Teachers who mentioned all three components were recognized to have a balanced view. However, one third of the teachers had a biased view, mentioning only 1 component. Many had an intermediate view, mentioning 2 components. Preference for the cognitive component, the disregard of the personal component, and the partial understanding of the environmental component were also discovered. To successfully facilitate creativity in gifted education, teachers' balanced view is essential. Thus the personal component and the environmental component should be emphasized to improve their understanding.

Burnett \& Procter (2004) sought to develop measurement instrument that provides teachers with a tool to observe the personal creativity characteristics of individual students. The instrument was developed by compiling a list of characteristics derived from the literature to be indicative of the personal characteristics of creative people. The list was then reduced by grouping like characteristics to 9 cognitive and dispositional traits that were considered appropriate for elementary students. The 9-item instrument was then administered in 24 classrooms to 6 and Year 7 students. Factor analysis revealed an eigenvalue greater than 1 and accounting for $63 \%$ of the variance. The results indicated that the creativity checklist has very high internal consistency and is a reliable measurement instrument $(\alpha$ $=.93)$.

Furthermore, Prabhu, Sutton and Sauser, (2008) hypothesized a conceptual model and tested the mediating and moderating role of intrinsic and extrinsic motivation respectively in the relationship between three personality traits (openness to experience, self-efficacy, and perseverance) and creativity. This study, conducted in a university setting from (124) students who did not finish study yet, the study administrated (What Kind of Person Are You? KOPAY consisting of (50) items designed to assess the individual's behavior and (NEO-FFI) scale to assess their openness for experience. The findings indicated that the potential mediating role of intrinsic motivation between creativity/openness to experience as intrinsic motivetion partially mediated this relationship. Self-efficacy was closely related to creativity, with intrinsic motivation completely mediating this relationship. Extrinsic motivation moderated the relationship between self-efficacy/creativity and perseverance/creativity and had a negative association with creativity.

Oral (2006) conducted a study to investigate the aspects of creativity among prospective teachers in Turkey. The study sample consisted of (140) male and female students of Akdeniz University, Faculty of Education. Regression analyses demonstrated that although creativity dimensions (Fluency, Flexibility, originality and elaboration) were not included in OSS in previous years, they are taken into consideration at moderate but significant levels in recent years; however, it is not sufficient to produce an educational reform for a creative, developed society.

1) Additionally, Kim (2008) conducted a study entitled "Underachievement and Creativity: Are Gifted Underachievers Highly Creative?" To answer this question the researcher reviews the available literature that suggests that the under achievement of gifted students may be tied to their inherent and unrecognized creativity. Apparently, many gifted students are underachievers and up to $30 \%$ of high school dropouts may be highly gifted. Finally, it reviews the studies and theories that have shown that once underachievers are placed in an environment that fosters their needs, with motivation, mentors, understanding, freedom, and responsibility, they can become highly productive.

2) In Malaysia, Habibollah, Rohani, Tengku, Jamaluddin and Vijay (2010) conducted a study to examine if a relationship exists between creativity and academic achievement and if the relationship differs between males and females. The sample of the study consisted of (153) male and female students (male = 105 and female $=48$ ) completed creativity test. Cumulative grade point average (CGPA) was used to select the participants. Creativity was measured using the Khatena-Torrance Creative Perception Inventory (KTCPI). Pearson Correlation analysis indicated that aspects of creativity are related to academic achievement. Moreover, the findings indicated that there are differences between males and females on some domains as the means of males performance on the innovation and artistry domains were higher, while it was higher for females on environmental sensitivity, intellectuality and independency domains.

Moreover, Kim and Van Tassel (2010) aimed to examine whether there is a relationship between creativity and behavior problems among underachievers. Forty-one elementary and 89 high school students and 4 teachers in Korea participated in this study. To achieve this aim three measures were used, those are, (Torrance Tests of Creative Thinking-Figural, Runco Ideational Behavior Scale [RIBS], and Scales for Rating the Behavioral Characteristics of Superior Students-Revised Edition [SRBCSS-R]), with their scores on a measure of behavior problems reported by their teachers. The results indicated that, among underachievers, there is a relationship between behaveioral problems 
and students' scores on the three measures of creative potential. Both underachievers and high achievers showed high scores on creative abilities test more than other students. Meanwhile, there were no significant statistical differences on both RIBS and SRBCSS-R.

Ai (1999) conducted a study in Spain to investigate the relationship between creativity and academic achievement and to examine the differences between males and females according to this relationship. The sample of the study consisted of (68) schools selected randomly. The instruments were administrated on (2264) male and female students. To achieve the aim of this study Torrance Tests of creativity thinking (TTCT) and AbediSchumacher tests of creativity test were administrated. The findings of the study indicated that creativity is related to achievement for both males and females. Moreover, males showed more flexibility than females while females were better in elaboration than males.

\section{Significance of the Study}

The importance of the current study is as follows:

1) Identifying the creativity characteristics displayed by high achievers and average achievers in regular schools since exploring those characteristics among students and its relation to achievement may help teachers in enhancing procedures of teaching to fit and support those variables (achievement and creativity characteristics).

2) Investigating the role of school type (private, public) in developing creativity among students and observing which system is the one developing the creativity characteristics among students.

\section{Procedural Definitions}

- Creativity Characteristics: Those are ( Fluency, mystery, fantasy, elaboration in thinking, problem sensitivity, independency, curiosity, originality in thinking, flexibility and sense of humor) in case of being assessed by the teacher above average on the scale of the creative characteristics quartet measurement, so that the average is above (3) for the item and (12) for the domain.

- High achievers: Students who achieve (80) and above on the school achievement test scores at the end of the schooling year of (2010/2011) in private and public schools in Jordan.

- Average achievers: Students who achieve less than (79) on the school achievement test scores at the end of the schooling year of $(2010 / 2011)$ in private and public schools in Jordan.

- Public school: Schools following the Jordanian Ministry of Education in academic, financial and administrative affairs and considered a property of the Jordanian state.

- Private Schools: Schools following private education department academic, financial and administrative affairs and owned by one person or a group of people.

\section{Study Question}

The objective of this study is represented in the following question:

- Are there any significant statistical differences in the creative characteristics among creative students in regular schools as perceived by teachers attributed to Academic
Achievement (Regular, Higher Achievers)?

- Are there any significant statistical differences in the creative characteristics among creative students in regular schools as perceived by teachers attributed to school type (public, private)?

\section{Methodology}

\section{Study Population}

The population of the study consisted of all private and public schools and all male and female students in (3-11) grades in Amman city for the schooling year 2011 .

\section{Participants}

The sample of this study consisted of (11) schools (7 private schools and 4 public schools). Sixty-seven teachers participated in assessing the creative traits among students regardless of their academic achievement. Noting that the assessed sample consisted of (176) male and female high achievers, (49) average achievers chosen intentionally.

\section{Study Instrument}

To achieve the aim of this study the researcher administrated (Al-Srour, 2011) scale to assess the creative characteristics among students, this scale is consisting of (48) items distributed on (12) items, those are (Fluency, mystery, fantasy, elaboration in thinking, problem sensitivity, independency, curiosity, intuittion, originality in thinking, adventure, flexibility and sense of humor), the scale has high rates of validity and reliability. To detect the validity content: instrument has been jugged by (5) of specialists in the areas of educational psychology and special the percentage of agreement was (.90).

Validity construction procedure:

The instrument was applied in pilot study $(\mathrm{n}=60)$ students, correlation coefficient between items and dimension has been reached, the coefficient values of the correlation coefficient were between $(.60-.82)$. Cronbach's alpha was used to detect the reliability of instrument, values of reliability coefficient on the dimensions in order are as follows: $(.60, .71, .79, .63, .76$, $.61, .60, .81, .76, .66, .68, .81)$. The value of consistency on all the paragraphs of the scale was (.84).

\section{Administration Procedures}

- The researcher met teachers who had a good knowledge of students since they had a long experience in teaching those students in previous years. Teachers were assigned to select students who display creative characteristics regardless of their academic achievement. Moreover, the researcher emphasized that teachers should choose students who are enrolled in at least two years in the school, teachers have been informed of the study objective, and that the information and results of the study will be used only for the purposes of scientific research.

\section{Significance of the Study}

The importance of the current study is as follows:

1) Identifying the creativity characteristics displayed by high achievers and average achievers in regular schools since exploring those characteristics among students and its relation to 
achievement may help teachers in enhancing procedures of teaching to fit and support those variables (achievement and creativity characteristics).

2) Investigating the role of school type (private, public) in developing creativity among students and observing which system is the one developing the creativity characteristics among students.

\section{Administration Procedures}

The researcher met teachers who had a good knowledge of students since they had a long experience in teaching those students in previous years. Teachers were assigned to select students who display creative characteristics regardless of their academic achievement. Moreover, the researcher emphasized that teachers should choose students who are enrolled in at least two years in the school, teachers have been informed of the study objective, and that the information and results of the study will be used only for the purposes of scientific research.

\section{Results}

To answer the study main question (Are there any significant statistical differences in the creative characteristics among creative students in regular schools as perceived by teachers attributed to academic achievement? The means and standard deviations were calculated on the sub-domains of the scale. Table 1 shows the results of the means and standard deviations on the sub-domains.

Table 1 shows differences in the means between high achievers and average achievers on all the creative characteristics for the favor of high achievers. Meanwhile, there were significant statistical differences on five domains (fluency, imagination, problem sensitivity, originality and intuition) for the favor of high achievers. Moreover, the findings showed that the most important creative characteristics according to achievement variable were curiosity and fluency while the least apparent domains were sense of humor and imagination.

It is noted in Table 2 that there are significant statistical differences on the variable of school type (public, private). The findings showed that there are differences on the following creative characteristics (Mystery, imagination, curiosity, adventure and sense of humor) for the favor of private schools. Moreover, there were differences in means on the following characteristics (fluency, problem sensitivity and independency) for the favor of public schools. However, (t) test results didn't show any significant differences except on independency domain for the favor of public schools and the least apparent characteristic is the sense of humor.

\section{Discussion}

The findings of the study indicated that there are differences in the means between high achievers and average achievers on all the creative characteristics for the favor of high achievers. Meanwhile, there were significant statistical differences on five domains (fluency, fantasy, problem sensitivity, originality and intuition) for the favor of high achievers. Meanwhile, there were no significant statistical differences on the domains and other creative characteristics. This result can be interpreted that traits such as fluency, fantasy, problem sensitivity, originality and intuition are related in its nature with high achievers. Those
Table 1.

Means, standards deviations (SDs) and (T) test results according to school type.

\begin{tabular}{|c|c|c|c|c|c|}
\hline variables & & $\mathbf{M}$ & $\mathbf{T}$ & SD & sig \\
\hline \multirow{2}{*}{ Fluency } & Public & 13.69 & 2.680 & 1.824 & \multirow{2}{*}{.103} \\
\hline & Private & 13.62 & & 2.233 & \\
\hline \multirow{2}{*}{ Mystery } & Public & 11.60 & 1.562 & 2.290 & \multirow{2}{*}{.213} \\
\hline & Private & 12.58 & & 2.476 & \\
\hline \multirow{2}{*}{ Imagination } & Public & 10.55 & .413 & 2.886 & \multirow{2}{*}{.521} \\
\hline & Private & 12.07 & & 3.014 & \\
\hline \multirow{2}{*}{ Elaboration } & Public & 12.55 & .469 & 2.609 & \multirow{2}{*}{.495} \\
\hline & Private & 12.74 & & 2.525 & \\
\hline \multirow{2}{*}{$\begin{array}{l}\text { Sensitivity to the } \\
\text { problems }\end{array}$} & Public & 12.98 & .489 & 2.528 & \multirow{2}{*}{.485} \\
\hline & Private & 12.76 & & 2.805 & \\
\hline \multirow{2}{*}{ Independently } & Public & 13.51 & *5.717 & 1.865 & \multirow{2}{*}{.018} \\
\hline & Private & 13.16 & & 2.426 & \\
\hline \multirow{2}{*}{ Curiosity } & Public & 13.49 & .458 & 1.990 & \multirow{2}{*}{.500} \\
\hline & Private & 14.16 & & 1.839 & \\
\hline \multirow{2}{*}{ Originality } & Public & 12.33 & .002 & 2.568 & \multirow{2}{*}{.967} \\
\hline & Private & 13.01 & & 2.574 & \\
\hline \multirow{2}{*}{ Intuition } & Public & 12.38 & .013 & 2.313 & \multirow{2}{*}{.910} \\
\hline & Private & 13.01 & & 2.485 & \\
\hline \multirow{2}{*}{ Adventure } & Public & 12.29 & .976 & 2.208 & \multirow{2}{*}{.325} \\
\hline & Private & 13.54 & & 2.473 & \\
\hline \multirow{2}{*}{ Flexibility } & Public & 12.58 & 2.194 & 2.070 & \multirow{2}{*}{.140} \\
\hline & Private & 13.09 & & 2.419 & \\
\hline \multirow{2}{*}{ Sense of Humor } & Public & 10.51 & .089 & 3.084 & \multirow{2}{*}{.766} \\
\hline & Private & 11.79 & & 3.227 & \\
\hline
\end{tabular}

Note: ${ }^{*}$ Significant at $p<.05$.

students usually have the ability to maintain and store information and therefore, increasing their fluency as they are capable of self regulation, facing problems and solving the difficult problems they may face. Furthermore, the related literature indicates that fantasy, originality and intuition are special characteristics of high achievers. Moreover, there were differences on the means of school type as the findings showed that that there are differences on the following creative characteristics (Mystery, fantasy, curiosity, adventure and sense of humor) for the favor of private schools and there were differences in means on the following characteristics (fluency, problem sensitivity and independency) for the favor of public schools. This result can be explained that traits such as fantasy, adventure and curiosity are linked to financial facilities. For example, to develop adventure trait among students the school must make trips ad sport facilities and this needs a lot of money that can be provided by private schools more than public schools. Furthermore, The sense of humor occurrence in private schools is higher than public school can be explained by the opportunity given by 


\section{A. AL-OWEIDI}

Table 2.

Means and standards deviations (SDs) and (T) test results according to academic achievement.

\begin{tabular}{|c|c|c|c|c|c|}
\hline Variables & & $\mathbf{M}$ & SD & $\mathbf{T}$ & sig \\
\hline \multirow{2}{*}{ Fluency } & High Achievement & 14.17 & 1.751 & \multirow{2}{*}{${ }^{*} 5.977$} & \multirow{2}{*}{.015} \\
\hline & Moderate Achievement & 12.27 & 2.343 & & \\
\hline \multirow{2}{*}{ Mystery } & High Achiever & 12.68 & 2.271 & \multirow{2}{*}{.453} & \multirow{2}{*}{.502} \\
\hline & Moderate Achievement & 11.22 & 2.624 & & \\
\hline \multirow{2}{*}{ Imagination } & High Achievement & 11.94 & 2.777 & \multirow{2}{*}{ *6.165 } & \multirow{2}{*}{.014} \\
\hline & Moderate Achievement & 10.71 & 3.547 & & \\
\hline \multirow{2}{*}{ Elaboration } & High Achievement & 12.98 & 2.502 & \multirow{2}{*}{.061} & \multirow{2}{*}{.805} \\
\hline & Moderate Achievement & 11.92 & 2.524 & & \\
\hline \multirow{2}{*}{ Sensitivity to the problems } & High Achievement & 13.39 & 2.323 & \multirow{2}{*}{${ }^{*} 10.705$} & \multirow{2}{*}{.001} \\
\hline & Moderate Achievement & 11.39 & 3.128 & & \\
\hline \multirow{2}{*}{ Independently } & High Achievement & 13.54 & 2.178 & \multirow[t]{2}{*}{.701} & \multirow[t]{2}{*}{.404} \\
\hline & Moderate Achievement & 12.57 & 2.363 & & \\
\hline \multirow{2}{*}{ Curiosity } & High Achievement & 14.17 & 1.924 & \multirow{2}{*}{.411} & \multirow{2}{*}{.522} \\
\hline & Moderate Achievement & 13.37 & 1.752 & & \\
\hline \multirow{2}{*}{ Originality } & High Achievement & 13.12 & 2.305 & \multirow{2}{*}{${ }^{*} 5.989$} & \multirow{2}{*}{.015} \\
\hline & Moderate Achievement & 11.96 & 3.068 & & \\
\hline \multirow{2}{*}{ Intuition } & High Achievement & 13.26 & 2.116 & \multirow{2}{*}{${ }^{*} 6.457$} & \multirow{2}{*}{.012} \\
\hline & Moderate Achievement & 11.65 & 2.847 & & \\
\hline \multirow{2}{*}{ Adventure } & High Achievement & 13.31 & 2.493 & \multirow{2}{*}{.169} & \multirow{2}{*}{.681} \\
\hline & Moderate Achievement & 12.71 & 2.327 & & \\
\hline \multirow{2}{*}{ Flexibility } & High Achievement & 13.17 & 2.156 & \multirow{2}{*}{.908} & \multirow{2}{*}{.342} \\
\hline & Moderate Achievement & 12.33 & 2.633 & & \\
\hline \multirow{2}{*}{ Sense of Humor } & High Achievement & 11.72 & 3.119 & 021 & 26 \\
\hline & Moderate Achievement & 10.55 & 3.392 & .831 & \\
\hline
\end{tabular}

Note: ${ }^{*}$ Significant at $p<.05$.

those schools for students to show jokes and give a sense of humor, while students in public schools are not allowed to show jokes and this is due to the character of the teacher, which prefer to work and seriousness in dealing. As for a independency characteristic, it was higher for public school students since teachers help students in carrying out their tasks personally and help them on self-regulation.

\section{Conclusion}

The findings of the current study confirmed that the teachers should prepare educational activities from curriculum and achieve it within the classroom to develop imaginative abilities and sense of humor in students; also the creative aspects of students in public schools need to be developed. Therefore, teachers may conduct some activities and add several teaching strategies to enhance and develop the creative characteristics among their students in public schools.

\section{REFERENCES}

Ai, X. (1999). Creativity and academic achievement: An investigation of gender differences. Creativity Research Journal, 12, 329-337. doi:10.1207/s15326934crj1204 11

Al-Srour, N. (2005). Teaching thinking in curriculum. Jordan: Wael Press.

Wu, C. H., Cheng, Y., Ip, H., \& McBride-Chang, C. (2005). Age differences in creativity: Task structure and knowledge base. Creativity Research Journal, 17, 321-326. doi:10.1207/s15326934crj1704_3

Habibollah, N., Rohani, A., Tengku, Aizan, H., Sharir, J., \& Kumar, V. (2010). Relationship between creativity and academic achievement: A study of gender differences. Journal of American, 6, 181-190.

Johnsen, S. (2004). Identifying gifted students: A practical guide. Mount Vernon, NY: Prufrock Press.

Kim, K., \& Van Tassel, B. (2010). The relation between creativity and behavior problems among underachieving elementary and high scholl students. Creativity Research Journal, 22, 185-193. doi: $10.1080 / 10400419.2010 .481518$

Kim, K. (2008). Underachievement and creativity: Are gifted underachievers highly creative? Creativity Research Journal, 20, 234-242. doi: 10.1080/10400410802060232

Lee, E., \& Seo, H. (2006). Understanding of creativity by korean elementary teachers in gifted education. Creativity Research Journal, 18, 237-242. doi:10.1207/s15326934crj1802 9

Myers, R., \& Torrance, P. (2003). What next? Futuristic scenarios for 


\section{A. AL-OWEIDI}

creative problem solving. Mount Vernon, NY: Prufrock Press.

Oral, G. (2006). Creativity of Turkish prospective teachers. Creativity Research Journal, 18, 65-73. doi:10.1207/s15326934crj1801 8

Prabhu, V., Sutton, C., \& Saser, W. (2008). Creativity and certain personality traits: Understanding the mediating effect of intrinsic moti- vation. Creative Research Journal, 20, 53-66.

doi:10.1080/10400410701841955

Proctor, R., \& Burnett, P. (2004). Measuring cognitive and dispositional characteristics of creativity in elementary students. Creativity Research Journal, 16, 421-429. doi:10.1080/10400410409534553 